\title{
Anatomical mysteries
}

\author{
Geoff Norman
}

Received: 10 March 2010/Accepted: 10 March 2010/Published online: 23 March 2010

(C) Springer Science+Business Media B.V. 2010

Learning anatomy has been a major and fundamental part of medical education ever since there were doctors. Unlike many other areas of medical science, anatomy knowledge has not become obsolete every 5 years; the individual bits of the human body are pretty well where they were back in Grecian times. But while the subject matter may not have changed all that much, the ways of teaching anatomy have undergone dramatic changes over the past few decades. While many schools still retain the cadaver dissection as a central component of anatomy learning and perhaps as a "right of passage" toward a professional role, dissection has been supplemented and often replaced by other technologies, ranging from prosected specimen in plastic to virtual reality simulations.

Regrettably, there is little evidence about the relative merits of one form of instruction or another. Certainly, some evidence suggests that, counter to our intuitions, the ability of computer-based instruction to permit rotation and multiple perspectives results in a reduction in learning, particularly for students with poor spatial ability (Garg et al. 2002, Levinson et al. 2007). Indeed, one conclusion from these studies is that the standard posterior-anterior figure from the anatomy book may well result in better learning than more elaborate or dynamic presentations. These findings are consistent with the "cognitive load" theories of learning which are a useful reality test for instructional technology aficionados. (Mayer, van Merriënboer and Sweller 2010). For example, Mayer has shown that dynamic representations, such as a platelet flowing through a coronary artery or a sodium molecule passing through a glomerulus membrane, actually result in less understanding than a series of still images under student control.

But these studies are really not grappling with the central issues of anatomy instruction. While we can anticipate that we will see more and more electrified anatomy instruction, just as we have in other areas of medical education, we should recognize from the outset that, at least until we all have 3-D glasses, these will remain as 2-dimensional projections

G. Norman $(\bowtie)$

McMaster University, MDCL 3519, 1200 Main St. W., Hamilton, ON L8N3Z5, Canada e-mail: norman@mcmaster.ca 
of 3-dimensional objects. Whether a computer or an anatomy text, these may not be the best thing to replace the dissection. ${ }^{1}$

Indeed, this may be the legitimate concern of many anatomists who view the replacement of dissection with more passive forms of instruction with disdain. Given that the cadaver remains central to instruction in many schools, yet is a very costly service to maintain, there are astonishingly few studies of the value of the cadaver, even compared to such obvious and low-tech alternatives as an ordinary textbook. Many have written about the role of dissection (McLachlan et al. 2004), yet much of this is more a case of rhetoric than evidence. Certainly, there is some evidence that students who have not enjoyed the delights of dissection are not handicapped (Prince et al. 2004) but this does not appear to have had any impact on the practice. But Prince's study, like many curriculum comparisons, does not allow for a clean comparison between one form of instruction and another; Maastricht students had access to prosected specimens, and other aids.

But whether one learns anatomy from a body, a book, or a laptop, is an issue of the means, not the end. The study by Wilhelmsson in this issue goes to the heart of the matter in examining students' perceptions of exactly what they are supposed to be learning anyway. The study highlights that students perceive that anatomy is too often a matter of memorizing the names of little details, and too seldom learning directed at understanding the relation between anatomy and clinical manifestations (signs and symptoms).

I fear that this reflects the role of anatomy teaching. Typically, it is taught during the earliest years, before students are involved in clinical learning, often by anatomists who themselves are not involved in clinical learning. Even in many PBL schools, anatomy learning is frequently carved off into its own niche. Anatomists, like most academics, view learning as an opportunity to "clone the species", and this perspective is reinforced by examinations that focus on the ability to recall the Latin names for the various bits and pieces on a cadaverous arm, leg or organ.

Perhaps this is not an entirely bad thing; words are the only way we have to communicate, and a person who cannot name anatomical parts may be hard pressed to go the next step and integrate these pieces into a coherent understanding of how the kidney, the heart, or the brachial plexus, works. Anatomists are aware of the problem, and many attempt to devise tests of "functional anatomy", but my limited experience with this question type suggests it is notoriously difficult to create.

But at a more fundamental level, I can't help but wonder if we have the right "gold standard" and, by implication, the right instructional methods. Do we really want students to be able to identify the bits on a dead specimen? If so, then dissection is a good way to go about it. But do we want them to learn from dead specimens at all? It seems to me that most physicians, who rarely get to see inside the body, or need to, might be better off with the kind of simplified schematics, replete with red arteries, blue veins, and pink spleens, that we see in textbooks and even in kid's toys, like the old visible man and woman toys. ${ }^{2}$

Surgeons, unlike most other specialties, really do get to see what things look like "inside". But even there, I suspect that there is not much correspondence between the living arteries and veins and the bits they had to cut apart when they were medical students,

\footnotetext{
1 The future may not be that distant. I write this from Mexico City, where I have just talked to an instructional designed who is designing 3-D digital anatomy software, to be used with the glasses.

2 Although I regret to mention the one failing student who was put into a remedial program, and when asked to comment on the circulatory system, began with "all the arteries are on one side and all the veins are on the other". Maybe for her a cadaver would have been a good idea.
} 
and much of their anatomy has to be relearned in the O.R. And the real thing has a good helper; arteries pulsate, veins don't.

It's a bit analogous to trying to navigate in a new country. If you were given a choice between Google Map or the schematic thrown up by your Blackberry GPS, (or for that matter, an old-fashioned paper map) and a photographic satellite image from Google Satellite, which would you pick? I suspect most would go with the map. Admittedly, sometimes the specific landmarks visible on Google Satellite and missing from the schematic might come in very handy, but most of the time, the extra information would be more noise than signal as you're careening down the unfamiliar highway. Similarly, it seems to me that most medical specialists may well get by with simplified schematics; indeed, may well be advantaged by such an approach. But this remains untested.

This "less is more" philosophy may apply beyond anatomy learning. When we discuss simulations, although we appear to view as axiomatic that higher fidelity is better (See Andreatta and Gruppen 2009), a number of studies (deGiovanni et al. 2009) have shown that expensive additions towards higher fidelity may result in modest gains incommensurate with the costs involved. There may be real economic benefits in approaching educational technology from a "satisficing" - enough to get the job done, rather than an optimizing — as much as we can afford, principle.

\section{References}

Andreatta, P. B., \& Gruppen, L. D. (2009). Conceptualising and classifying validity evidence for simulation. Medical Education, 43, 1028-1035.

deGiovanni, D., Roberts, T., \& Norman, G. R. (2009). Relative effectiveness of high- versus low-fidelity simulation in learning heart sounds. Medical Education, 43, 661-668.

Garg, A. X., Norman, G. R., Eva, K. W., Spero, L., \& Sharan, S. (2002). Is there any real virtue of virtual reality? The minor role of multiple orientations in learning anatomy from computers. Academic Medicine, 77, S97-S99.

Levinson, A. J., Weaver, B., Garside, S., McGinn, H., \& Norman, G. R. (2007). Virtual reality and brain anatomy: A randomised trial of e-learning instructional designs. Medical Education, 41, 495-501.

McLachlan, J. C., Bligh, J., Bradley, P., \& Searle, J. (2004). Teaching anatomy without cadavers. Medical Education, 38, 418-424.

Prince, K. J., van Eijs, P. W., Boshuizen, H. P., van der Vleuten, C. P., \& Scherpbier, A. J. (2004). General competencies of problem-based learning (PBL) and non-PBL graduates. Medical Education, 38, 418424.

van Merriënboer, J. J., \& Sweller, J. (2010). Cognitive load theory in health professional education: Design principles and strategies. Medical Education, 44, 85-93. 